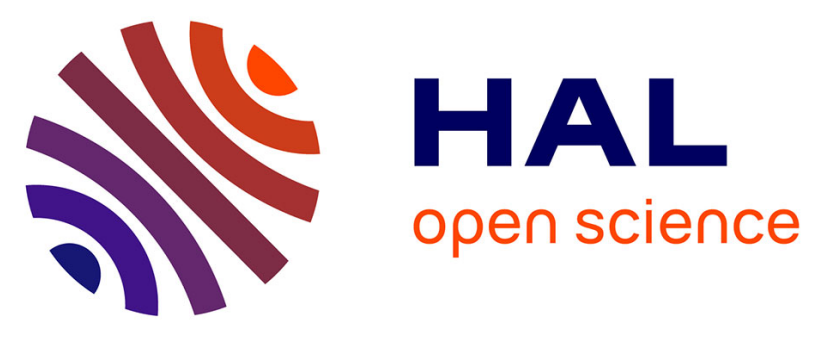

\title{
Sensitivity and gene expression profile of fresh human acute myeloid leukemia cells exposed ex vivo to AS602868
}

Lars Petter Jordheim, Adriana Plesa, Michel Dreano, Emeline Cros-Perrial, Céline Keime, Stéphanie Herveau, Delphine Demangel, Julie A. Vendrell, Charles Dumontet

\section{To cite this version:}

Lars Petter Jordheim, Adriana Plesa, Michel Dreano, Emeline Cros-Perrial, Céline Keime, et al.. Sensitivity and gene expression profile of fresh human acute myeloid leukemia cells exposed ex vivo to AS602868. Cancer Chemotherapy and Pharmacology, 2010, 68 (1), pp.97-105. 10.1007/s00280-0101458-y . hal-00624174

\section{HAL Id: hal-00624174 https://hal.science/hal-00624174}

Submitted on 16 Sep 2011

HAL is a multi-disciplinary open access archive for the deposit and dissemination of scientific research documents, whether they are published or not. The documents may come from teaching and research institutions in France or abroad, or from public or private research centers.
L'archive ouverte pluridisciplinaire HAL, est destinée au dépôt et à la diffusion de documents scientifiques de niveau recherche, publiés ou non, émanant des établissements d'enseignement et de recherche français ou étrangers, des laboratoires publics ou privés. 
Sensitivity and Gene Expression Profile of fresh human acute myeloid leukemia cells exposed ex vivo to AS602868

Running title: Gene expression profile of AS602868

Lars Petter Jordheim ${ }^{1,2,3}$, Adriana Plesa ${ }^{4}$, Michel Dreano ${ }^{5}$, Emeline Cros-Perrial ${ }^{1,2}$, Céline Keime $^{3,6}$, Stéphanie Herveau ${ }^{1,2}$, Delphine Demangel ${ }^{3}$, Julie A Vendrell ${ }^{3}$ \& Charles Dumontet $^{1,2,3,4}$

${ }^{1}$ Université Lyon 1, ISPB, Lyon, F-69003, France

2 INSERM, U590, 8 avenue Rockefeller, 69008 Lyon, France

${ }^{3}$ LCMT, ProfileXpert, Lyon, F-69008, France

${ }^{4}$ Hematology Laboratory, Hospices Civils de Lyon, Lyon, France

${ }^{5}$ Merck Serono S.A., Geneva, Switzerland

${ }^{6}$ PRABI, Université Claude Bernard Lyon 1, Villeurbanne, France

Correspondence should be addressed to:

Lars Petter Jordheim, INSERM U590, Laboratoire de Cytologie Analytique, Faculté de Médecine Rockefeller, Université Claude Bernard Lyon I, 69008 Lyon, France, Telephone: +334 787771 23, e-mail: jordheim@yahoo.com. 


\section{ABSTRACT}

Purpose: The need for new treatment options for acute myeloid leukemia (AML) is increasing. AS602868 is a novel investigational drug with reported activity on AML cells. Methods: We studied gene-expression profiles in AML-blasts exposed to AS602868 in order to better understand its mechanism of action. We analysed the in vitro cytotoxicity of AS602868 alone or in combination with daunorubicin, etoposide or cytarabine. To document AS602868-induced IKK2 inhibition in fresh AML cells, a flow cytometry analysis of I $\mathrm{B}$ was performed. Finally the effect of AS602868 on gene expression in fresh AML cells was analysed. Results: The results show that AML cells are globally as sensitive to AS602868 as they are to cytarabine, with large interindividual variations. Combinations with conventional antileukemic agents showed enhanced cytotoxic activity in subsets of patients. IKK2 appeared to be effectively inhibited by $100 \mu \mathrm{M}$ AS602868 in fresh leukemic cells. Gene expression profiling and Gene Ontology analyses identified several groups of genes induced/inhibited by exposure to AS602868 and/or exhibiting a correlation with sensitivity to this agent in vitro. Of note expression of several genes related to immune function was found to be significantly altered after exposure to AS602868. Conclusion: These data suggest that AS602868 is cytotoxic against fresh human AML blasts and provide insights regarding the mechanisms of cytotoxicity.

Keywords: Acute myeloid leukemia, AS602868, gene expression, microarray, sensitivity 


\section{INTRODUCTION}

Acute myeloid leukemia (AML) is an aggressive hematologic malignancy that requires treatment with intensive chemotherapy for cure. While the majority of patients with AML achieve a complete remission with induction therapy, greater than half of these subsequently relapse and ultimately die of the disease [1]. Relapse is thought to occur because of the failure of chemotherapy to eradicate leukemia stem cells. Current therapies consist in induction chemotherapy, usually a cytarabine/anthracycline combination, followed by consolidation therapy which is required to prevent relapse. Other commonly used compounds include etoposide, anthracycline analogues or mitoxantrone. There are few novel agents in the treatment of adult AML, and only a small subset of patients can be offered curative therapies and for most patients, particularly for the elderly who do not have access to intensive consolidation therapies or allogeneic stem cell grafting, current chemotherapies mainly result in short lasting remissions. A large majority of elderly patients die of their disease.

The nuclear factor $\kappa \mathrm{B}(\mathrm{NF}-\kappa \mathrm{B})$ transcription factor pathway has been shown to be implicated in the control of diverse cellular processes, including transformation, induction of proliferation, suppression of apoptosis, cell invasion and angiogenesis [2]. NF- $\kappa \mathrm{B}$ confers significant survival potential in a variety of tumors, including AML [3, 4]. Accumulating evidence strikingly supports that the NF- $\mathrm{B}$ pathway which regulates cell survival also suppresses the apoptotic potential of chemotherapeutic agents and contributes to drug resistance [5]. Therefore, direct or indirect inhibition of NF- $\kappa B$ is likely to have antiproliferative activity on

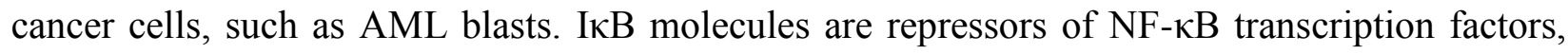
and their phosphorylation by IкB kinase 2 (IKK2, IKBKB, IKK $\beta$ ) induces their ubiquitination and subsequently their proteasomal degradation resulting in NF- $\mathrm{BB}$ translocation [6]. Conversely, inhibition of IKK2 maintains the inhibition of NF- $\kappa$ B by IкB. This has led to the development of IKK2 inhibitors [6, 7]. AS602868 is an anilino-pyrimidine derivative and adenosine triphosphate competitor with an in vitro $50 \%$ inhibitory concentration (IC50) of $60 \mathrm{nM}$ toward purified 
constitutively active IKK2 (IKK2ee). AS602868 displays no or limited inhibitory effects on IKK1 or on a large panel of recombinant kinases. It blocks the phosphorylation of I $\mathrm{B}$ as well as subsequent NF- $\kappa \mathrm{B}$ activation in various cell lines and in cells from patients with acute myeloid leukemia [8, 9]. Finally, AS602868 inhibits cell cycle progression and induced apoptosis in multiple myeloma cell lines, confirming its therapeutic interest as monotherapy $[10,11]$.

To analyze whether NF-кB inhibition could potentiate the effect of chemotherapy, preliminary pharmacological experiments have been performed with AS602868 in combination with the topoisomerase 1 inhibitor irinotecan or its active metabolite $\mathrm{SN}-38$ both in vitro and in vivo [12]. In HT-29 xenografts in nude mice, AS602868 had no significant effect on tumor growth by itself, while it was able to enhance the antitumor effect of irinotecan in a dosedependent manner. Co-treatment of AS602868 with irinotecan allowed a 3-fold reduction of irinotecan dose without a significant loss in antitumor activity. Ex vivo tumor analyses as well as in vitro studies on HT-29 cells showed that AS602868 impaired irinotecan-induced NF-kB activation, enhanced cell cycle arrest and apoptosis, reduced tumor cell proliferation and tumor vascularisation. Preliminary results showed that AS602868 is able to potentiate the effect of etoposide but also of aracytin and doxorubicin on AML blasts as well as the effect of etoposide or vincristine in cutaneous T-cell lymphoma [9, 13]. Additional interest for AS602868 in the treatment of AML is related to its inhibition of Flt3 $[14,15]$.

Gene expression profiling is a high throughput screening method used to identify multiple gene expression in a given sample. The comparison of expression profiles between samples can then be correlated with a given biological phenomenon. This approach has proven to be interesting to define molecular subgroups of patients at diagnosis ("expression signatures"), to define the effect of a bioactive molecule (biomarker approach) or to define prognostic or predictive profiles. In the context of determining biomarkers of activity and/or toxicity, pangenomic screening is a potentially interesting approach. 
In order to increase the knowledge on the activity and the mechanism of action of the IKK2 inhibitor AS602868, we performed gene expression profiling experiences on clinical samples exposed to this compound in vitro. The present study was conducted to provide data regarding the effect of AS602868 on the expression profiles in fresh human AML cells, and to correlate the baseline expression profile of fresh AML cells with their sensitivity to AS602868 in vitro.

\section{MATERIAL AND METHODS}

\section{Preparation of leukemic blasts}

Biological samples were obtained from 61 patients with AML at diagnosis $(n=32)$ before initiation of therapy or at relapse $(n=29)$, all followed in the Hematology Department of the Hospices Civils de Lyon, France. Patient characteristics are shown in Supplemental Table 1. Approval was obtained from Lyon Protocol Review Board, and written informed consent was provided according to the Declaration of Helsinki. Mononuclear cells including leukemic cells were isolated by Ficoll-Hypaque sedimentation from peripheral blood $(n=56)$ and bone marrow $(\mathrm{n}=5)$. The median percentage of blast cells in the preparations was 76\% (range: 5-99\%). Depending on the arrival of samples, they were assigned to four different groups (A-D). Fifty-one samples were used for in vitro sensitivity studies to AS602868 alone (groups B, C and D), 12 for sensitivity to combinations in vitro (group B), 10 for $\mathrm{I} \kappa \mathrm{B} \alpha$ determination by flow cytometry (group A) and 20 for gene expression profile studies (group D).

\section{Determination of in vitro sensitivity to AS602868}

Fresh leukemic blasts were incubated in RPMI 1640 supplemented with $10 \%$ fetal calf serum (FCS) and different concentrations of studied drugs alone or in combinations for 18 hours. Cells were then stained with annexin V / propidium iodide (Roche) and analysed by flow

activated cell sorting (FACS) on a Becton Dickinson FacsCalibur ${ }^{\circledR}$. Apoptotic cells were defined by annexin $\mathrm{V}$ positive cells, irrespective of their propidium iodide status. Results are expressed as 
the increase of the apoptotic cell population (annexin $\mathrm{V}$ positive) substracted for control values (unexposed cells incubated under the same conditions).

\section{Flow cytometry analysis}

Total blood from AML samples was incubated with DMSO or AS602868 $100 \mu \mathrm{M}$ for 2 hours at $37^{\circ} \mathrm{C}$, and thereafter for another 15 minutes in absence or in presence of a combination of PMA $(1 \mu \mathrm{M})$ and ionomycin $(500 \mathrm{ng} / \mathrm{ml})$. The incubation with PMA and ionomycin for 15 minutes has previously been shown to induce phosphorylation of IKK [16]. Samples were diluted in Lyse/Fix Buffer (BD Phosflow) and stored at $-80{ }^{\circ} \mathrm{C}$. Flow cytometry analysis was performed for the determination of $\mathrm{I} \kappa \mathrm{B} \alpha$ expression using I $\mathrm{K}$ - $\alpha$ mouse monoclonal antibody (L35A5, 1:400 dilution, Cell Signaling Technology, Danvers, MA) and Alexa Fluor 488 F(ab')2 fragment of goat anti-mouse $\operatorname{IgG}(\mathrm{H}+\mathrm{L}, 1: 2000$ dilution, Cell Signaling Technology, Danvers, MA) as secondary antibody. Briefly, cells were thawed, then permeabilized using ice cold $90 \%$ methanol for 30 minutes on ice, washed and successively stained by incubating cells 1 hour at room temperature for intracellular IкB- $\alpha$ and secondly 30 minutes in the dark for IgG-Alexa488. Finally, the cells were stained with the surface antibodies (CD45 PerCPcy5.5, clone 2D1, BD; CD3 PE, clone Sk7, BD; CD19 APC, clone SJ25C1, BD; CD4 PE, clone 13B8.2, Beckman Coulter; CD8 APC, clone Sk1, BD; CD34 APC, clone 8G12 anti HPCA2, BD) during 15 minutes at room temperature. Four colour analyses were performed using a CD45/SSC gating strategy and multiparametric analysis of CD3, CD4, CD8, CD19, CD34 and CD45 low blasts cells as well as I $\mathrm{B}-\alpha$ staining. For acquisition and analysis of data we used a Becton Dickinson FacsCalibur ${ }^{\circledR}$ and CellQuest Pro software.

\section{Toxicity on hematopoietic precursors}

The effect of AS602868 on colony-forming cells (CFCs) and long-term culture initiating

cells from human hematopoietic precursors was described previously [17]. Viability was determined by trypan blue exclusion count and proliferation by Uptiblue assay. 


\section{In vitro exposure to AS602868 for gene expression profile study}

Fresh leukemic blasts $\left(6.10^{6}\right)$ were exposed to DMSO-solubilised AS602868 (10 $\left.\mu \mathrm{M}\right)$ or DMSO (identical volume) in RPMI 1640 supplemented with $10 \%$ FCS for 6 hours at $37{ }^{\circ} \mathrm{C}$ in $5 \%$ $\mathrm{CO}_{2}$ atmosphere.

\section{$\underline{\text { mRNA extraction }}$}

After incubation with AS602868, cells were placed in lysis solution for RNA extraction. Total RNA from leukemic cells was extracted using the RNeasy Mini Kit (Qiagen, Hilden, Germany) according to the manufacturer's recommendations and subsequently quantified on a Nanodrop ND-1000 spectrophotometer (Nanodrop Technologies, Wilmington, DE, USA). RNA integrity was verified using the BioAnalyser $2100^{\mathrm{TM}}$ (Agilent Technologies, Palo Alto, CA, USA).

\section{$\underline{\text { Pangenomic array experiments }}$}

One-color labeled cRNAs were generated from 200 ng of total RNA using the Low RNA Input Amplification Kit (Agilent Technologies) according to the instructions of the manufacturer. Labeled cRNA were hybridized overnight to Whole Human Genome 4 x 44K microarrays. After washing, microarrays were scanned using the Agilent model G2505B microarray scanner, and data extracted by Feature Extraction software, version 9.5. The default settings were used to scan the microarrays.

\section{Normalization and analysis of microarray data}

The quantile normalization method was used to normalize microarray data [18]. Two comparisons were performed for the analysis of differentially expressed genes between samples. First, samples exposed to AS602868 in vitro were compared to the identical samples exposed to DMSO only (paired samples) using a modified Students $t$-test that uses an empirical Bayesian approach to improve error estimates for individual genes by using information from other genes [19]. Secondly, samples considered to be "sensitive" to AS602868 in vitro were compared to those considered to be "insensitive" samples (unpaired samples). For each comparison a list of genes was chosen when the significance value was less than 0.01 . In the next step, the biological 
relevance of these differentially expressed genes was analysed using Gene Ontology [20]. Microarray data are available on Gene Expression Omnibus (GSE1985).

\section{RESULTS}

\section{$\underline{\text { In vitro sensitivity to AS602868 }}$}

Fifty-one samples were evaluable for in vitro sensitivity to various concentrations of AS602868 and AraC (Supplemental Table 2). All samples were assayed for sensitivity to $30 \mu \mathrm{M}$ AS602868 inducing a mean percentage of annexin V positive cells of 24.65 , with a median value of 26.42 (range: $-6.95-71.58$ ). These values are comparable to those obtained with 20 samples exposed to $100 \mu \mathrm{M}$ AraC (mean: 27.70, median: 21.49, range: -0.33-74.29).

For 9 of the 19 samples incubated with several concentrations of AS602868, we observed a dose-effect correlation with $\mathrm{R}^{2}>0.6$ (range 0.62-0.99). For 8 samples, no correlation was observed $\left(R^{2}<0.6\right)$, whereas for one sample we observed a negative correlation $\left(R^{2}=0.92\right)$. Among the 20 samples analysed in group D, we observed a positive correlation for 6 samples (range of $R^{2}$ : $\left.0.75-0.98\right)$, negative correlation for one sample $\left(R^{2}=0.64\right)$ and no correlation for the last 13 samples. For the samples of groups B and C, we did not observe any correlation between sensitivity to AS602868 and to $\operatorname{AraC}\left(\mathrm{R}^{2}<0.6\right)$.

For the 20 samples of group D, we observed a good correlation between sensitivity to 100 AraC and $10 \mu \mathrm{M}$ of AS602868 $\left(\mathrm{R}^{2}=0.74\right), 3 \mu \mathrm{M}$ AS602868 $\left(\mathrm{R}^{2}=0.76\right)$ and $1 \mu \mathrm{M}$ AS602868 $\left(\mathrm{R}^{2}=0.75\right)$ but not with 30 or $0.1 \mu \mathrm{M}$ AS602868. The sensitivity at a concentration of $10 \mu \mathrm{M}$ AS602868 in this group was used to distinguish between "sensitive" and "insensitive" samples for the expression profile study. The cutoff in terms of annexin V increase was $25 \%$. Using the same cutoff for AraC-induced annexin V, we obtained the same groups of "sensitive" and "insensitive" samples (Figure 1). Using other concentrations for the determination of "sensitive" and "insensitive" samples only slightly modified the groups (data not shown).

\section{$\underline{\text { In vitro sensitivity in combination with other drugs }}$}


Samples of fresh AML blasts from 12 patients were used to study the in vitro sensitivity to AS602868 in association with AraC, etoposide and daunorubicin. Two series of experiments using different concentrations of AS602868 were performed (Supplemental table 3). Correlations were observed between the sensitivity to 1 or $30 \mu \mathrm{M}$ AS602868 and 1 or $10 \mu \mathrm{M}$ etoposide and between 1 and $30 \mu \mathrm{M}$ AS602868 ( $\mathrm{R}^{2}>0.6$, range: 0.6082-0.9465). In the first series (6 patients), where three concentrations of AS602868 were evaluated in association with one concentration of AraC, etoposide or daunorubicin, we observed higher cytotoxicity of combinations than for one of the molecules alone only for the combination of $10 \mu \mathrm{M}$ daunorubicin with $0.3,3$ or $30 \mu \mathrm{M}$ AS602868 for two patients (Figure 2A, B and C). In the second series (6 patients), where two concentrations of AS602868 were evaluated in association with two concentrations of AraC, etoposide or daunorubicin, we observed increased annexin V staining with AraC for two patients, and with etoposide and daunorubicin for two patients (Figure 2D, E and F).

\section{$\underline{\text { In vitro toxicity on hematopoietic precursors }}$}

Mononuclear cells from normal human bone marrow were exposed to different concentrations of AS602868, and viability and proliferation were evaluated (Table 1). The viability was not modified whereas the IC50 values for proliferation were $5 \pm 0.89$ and $2.5 \pm 0.44$ $\mu \mathrm{M}$ at 4 and 7 days respectively. Low concentrations of AS602868 (0.1-1 $\mu \mathrm{M})$ stimulated the colony formation of total and GM mononuclear cells, but had no effect on CD34 positive cells or the long-term culture initiating cells. At higher concentrations $(5-50 \mu \mathrm{M})$, these parameters were modified.

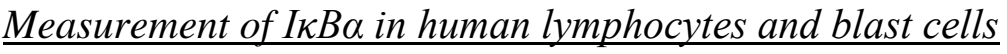

When active, IKK2 induces the phosphorylation and the degradation of IKB $\alpha$. IKK2 can be stimulated by PMA and ionomycin and intracellular content of I $\mathrm{B} \alpha$ can be detected by flow cytometry analysis. We developed a method to quantify phosphorylated and unphosphorylated $\mathrm{I} \kappa \mathrm{B} \alpha$ in lymphocytes and blasts from AML patients and used this to study samples from 10 patients (Figure 3). In lymphocytes, we observed decrease of I $\mathrm{B}$ content by fluorescence after 
incubation with PMA/ionomycin in all samples. This decrease, reflecting the degradation of I $\mathrm{B} \alpha$ after phosphorylation by IKK2, was partially inhibited in samples co-incubated with AS602868 indicating IKK2-inhibition by this compound. However, in blasts from the same patients, IкB $\alpha$ degradation induced by PMA was only observed in samples from five patients after incubation with PMA/ionomycin. This degradation was reverted by co-incubation with AS602868. In addition, modestly increased signal for $\mathrm{I} \kappa \mathrm{B} \alpha$ was observed after incubation of lymphocytes from the other patients with AS602868, indicating a higher baseline level of IKK2 activity in these cells than in the other patients or in the lymphocytes from the corresponding patients.

\section{Microarray results}

A total of 40 samples corresponding to the cells of the 20 patients exposed to DMSO or $10 \mu \mathrm{M}$ AS602868 in vitro, were processed for RNA extraction and pangenomic analysis. In a first analysis, we compared samples that were sensitive and insensitive to AS602868 in vitro as identified in the sensitivity assays (Figure 1 and Supplemental Table 2). Two-hundred and eighty genes were found to be differentially expressed between the samples from these two groups ( $\mathrm{p}<0.01$ and $\log 2$ fold-change $>1$ or $<-1$, Supplemental Figure 1A, Supplemental table 4). Log2 fold-changes varied between -4.2 and 3.5. Gene ontology analysis of the 280 genes was performed for major "Cellular components", "Biological processes" and "Molecular functions". This analysis shows that genes differently expressed in sensitive versus insensitive samples show significant enrichment in genes coding for membrane proteins (intrinsic, integral, lipid raft), immune response and response to external stimulus/wounding, organismal physiological processes, receptor and signal transduction activity, including G-protein coupled receptor activity (Supplemental tables 5, 6 and 7).

In a second analysis, we compared gene expression in samples exposed to DMSO alone or AS602868 in vitro in order to determine which genes were regulated by exposure to this agent. Three hundred and fifty four genes were found to be differentially expressed after exposure to 10 $\mu \mathrm{M}$ AS602868 in vitro (Supplemental Figure 1B and Supplemental table 8). Here, $\log 2$ fold- 
changes varied between -2.93 and 2.61. Gene ontology analysis of the 354 genes was performed as above, and this analysis shows that genes differently expressed in AS602868 treated versus untreated samples show significant enrichment in genes coding for extracellular space, immune response, G-protein coupled receptors, regulation of physiological and organismal processes, programmed cell death, response to external stimuli, stress or wounding, protein and RNA binding (Supplemental tables 9, 10 and 11).

\section{DISCUSSION}

AS602868 displayed significant apoptotic-inducing activity on fresh human myeloid leukemic blasts, with median activity comparable to that observed with the same concentrations of $\mathrm{AraC}$, a reference compound in AML. In the 51 samples incubated with $30 \mu \mathrm{M}$ AS602868, the mean increase of the annexin $\mathrm{V}$ positive fraction was $26.02 \%$. However, a great variability was observed as individual samples showed from -6.95 to $71.58 \%$ positive cells at this concentration (Suppelemental Table 2). Insofar as the clinical use of a compound depends on its therapeutic index, we also evaluated the toxicity of AS602868 on hematopoietic precursors. Inhibition of $50 \%$ of the cell proliferation was obtained with 5 and $2.5 \mu \mathrm{M}$ AS602868. Taken into account the differences in methodology between the study on hematopoietic precursors and fresh lymphoblasts, we find these results rather promising as for a favourable therapeutic index of AS602868. This should, however, be confirmed by extended in vivo studies. In addition, given the properties of $\mathrm{NF}-\kappa \mathrm{B}$, its inhibition might have important consequences in vivo. However, initial reports on other compounds inducing NF- $\mathrm{BB}$ inhibition indicate good tolerance at least in mice and dogs [21].

As the treatment of AML is based on a combination of several drugs, we assessed the sensitivity of blast cells to AS602868 in combination with AraC, etoposide and daunorubicin, all three used in the induction treatment of AML patients. Preliminary experiments on incubations of blast cells with different combinations of these molecules, suggest a greater efficacy of some of 
these combinations in subsets of patients (Figure 2). Analyses of larger series are required to identify parameters correlated with enhanced sensitivity to these combinations.

Evaluation of I $\mathrm{B} \mathrm{B} \alpha$ levels by flow cytometry is feasible in AML samples after in vitro incubation with various compounds and conservation by freezing. We evaluated IкB $\alpha$ levels in lymphocytes and blasts incubated with AS602868. Baseline I $\mathrm{B} \alpha \alpha$ levels are relatively similar in lymphocytes from different patients (mean fluorescence intensity (MFI): 44-117) and reproducibly altered by PMA/ionomycin stimulation (range of modified $\mathrm{I} \kappa \mathrm{B} \alpha$ level: -82.8-$41.1 \%$, Figure 3). Lymphocytes can therefore be used as internal controls for studies of modulation in haematological malignancies. I $\mathrm{B} \alpha \alpha$ levels vary significantly in blast cells of different AML patients, both in terms of baseline levels (MFI: 35-157), sensitivity to PMA/ionomycin (range of modified IאB $\alpha$ level: -76.5-91.4\%) and sensitivity to AS602868. These are imporant characteristics (in addition to selectivity and low variability) for this parameter to be used as a biomarker in a clinical trial of AS602868 in AML patients. Unfortunately, we did not have the cytotoxicity values for AS602868 in the fresh samples used for the biomarker assay, and could therefore not establish correlations between variations in I $\mathrm{B} \alpha$ levels and sensitivity to AS602868.

In the study on differentially expressed genes between sensitive and insensitive samples and between baseline and post-treatment samples, we used a total of 20 fresh adult AML samples assigned as sensitive or insensitive. While studying the difference in expression profile for the two groups of 10 samples, we observed a more than 3-fold higher expression in insensitive cells than in sensitive cells of 11 genes, and a more than 3-fold higher expression in sensitive cells than in insensitive cells for 2 genes (Supplemental table 4). GO analysis of the differentially expressed genes showed significant differences in membrane associated genes (intrinsic or integral, lipid raft, G-coupled receptor activity, signal transducing activity), immune response and response to external stimulus or wounding. Taken together, the following points can be underlined: (i) There is no clear correlation between in vitro sensitivity and altered expression of components of the 
IKK/NFkb pathway in this series of samples, since these genes or related genes are not found in the list of differentially expressed genes. When looking at differential expression of other kinases, LERK-7, CCRK and PRKCB1 are found to be expressed 2-fold more in insensitive cells than in sensitive cells while LTK is expressed at a higher level in sensitive cells. (ii) Several chemokine ligand genes (CXCL1, CXCL7) or chemokine receptor genes (CCR3, CCRL2) were found to be differentially expressed. (iii) Several solute carrier genes were expressed at higher levels in insensitive cells (SLC35A2, SLC25A37, SLC35E1 and SLC26A8). (iv) Other solute carrier genes (SLC44A5 and SLC5A9) were more highly expressed in sensitive samples. (v) CD52, the target of alemtuzumab, was found to be expressed at a higher level in insensitive cells. If AS602868 was to be tested in lymphoproliferative diseases such as chronic lymphocytic leukaemia, this observation should be confirmed in this setting. While AS602868 was developed as an IKK inhibitor, it also potently inhibits other kinases, such as Aurora A or Flt3 with IC50 values of $5.1 \mu \mathrm{M}$ and $2.4 \mu \mathrm{M}$ respectively (data not shown). This might suggest that the activity of AS602868 on tumor cells is due to several mechanisms that should be validated. In particular, mutations in these kinases could modify the cytotoxic activity of AS602868. We only obtained the Flt3 status for 13 samples and could not correlate this with sensitivity. In addition, the inhibition of Flt3 by AS602868 has been shown to be similar for all forms of Flt3 and therefore Flt3 status should not interfere with the activity of AS602868 [15].

Limitations of this approach include: a) the fact that samples were arbitrarily considered as "sensitive" or "insensitive" to AS602868 on the basis of a given concentration; b) the choice of annexin $\mathrm{V}$ induction to evaluate in vitro cytotoxicity; c) the number of samples analysed. The choice of a $10 \mu \mathrm{M}$ concentration is supported by the fact that this concentration has previously been shown to be the median cytotoxic concentration in this assay. These preliminary data could be confirmed on larger series, by real-time reverse transcription PCR on candidate genes, or by siRNA approaches to explore mechanistic links. In the context of a clinical trial these genes could 
be compared to the response observed in patients and help determine a profile correlated with sensitivity in the clinic.

We used the same 20 samples to study expression profiles after incubation with DMSO (vehicle) or $10 \mu \mathrm{M}$ AS602868. A total of 354 genes were found to be differentially expressed, with a greater than 1.5-fold increase for 10 genes and a greater than 2 -fold decrease for 7 genes (Supplemental table 8). Gene ontology analysis of the differentially expressed genes showed significant differences in extracellular space, immune response and response to external stimuli, G-protein coupled receptors, protein and RNA binding. For this part of our study, we highlight the following: (i) There is no clear correlation between exposure to AS602868 and expression levels of components of the IKK/NFK pathway in this series of samples. These genes or related genes were not found in the list of differentially expressed genes, with the exception of inhibitor of kappa light polypeptide gene enhancer in B-cells, kinase epsilon (IкBKE), for which the expression was reduced 1.26-fold. When looking at differential expression of other kinases, PAI2 was down-regulated after exposure to AS602868 while SNF1LK, PDPK1, RIOK3, JOSD1, MAP2K1IP1, PANK3, ADRBK1, CLK3, PRKA, AKAP8L and CLK1 were overexpressed. Variations in the level of expression of these kinases were moderate, since they were less than 2fold. (ii) Several chemokine ligand genes (CXCL10, CCL3, CCL3L3, CCL2, CCL4, CXCL1 and CCL8) or chemokine receptor genes (CCR) were found to be decreased by AS602868 while CKLF was moderately induced. (iii) The solute carrier SLC2A6 was inhibited by AS602868 while ZNT-1, GABA and SLC3A1 were induced by AS602868. (iv) Some serpin-related genes were found to be differentially expressed after exposure to AS602868, including PAI-2, SERPINB2 and SERPINC1. Among heat-shock proteins, two Hsp40 homologues, DNAJB6 and DNAJB14, were found to be moderately induced by exposure to AS602868. Additional preclinical data using siRNA could help to validate the role of certain kinases or other target genes in the cytotoxicity of AS602868 against AML cells. Such a study would be of great value 
since it could contribute to the identification and validation of novel targets in this disease, and therefore contribute to the development of novel compounds.

As for the first analysis, limitations of this study include the fact that a single concentration $(10 \mu \mathrm{M})$ and a single exposure time were explored, and that the number of samples analysed was relatively low. On the basis of these preliminary data it would be worthwhile to analyze candidate genes at different time points and using a range of concentrations by real-time reverse transcription PCR (rt-PCR), either in model leukemic cell lines or in fresh leukemic samples. Of note, the strong variation in CYP450 B1 could be related to the metabolism of AS602868.

A striking finding in this work is the influence of AS602868 on the expression of immune related genes and the influence of immune related genes on in vitro sensitivity to AS602868. Although established in the context of pathological myeloid cells, rather than on normal lymphoid cells, this observation raises the possibility that AS602868 may possess immunomodulatory properties. 


\section{ACKNOWLEDGEMENTS}

LPJ received grant from Medeco's Stiftelse. This study was supported by research funding from Merck-Serono International S.A. company to Charles Dumontet. The authors acknowledge Dr Véronique Maguer-Satta for studies on hematopoietic precursors.

\section{CONFLICTS OF INTEREST}

Michel Dreano is an employee of the Merck-Serono International S.A. company, whose IKK2 inhibitor is used in this study. Charles Dumontet received research funding from Serono. 


\section{REFERENCES}

[1] Tallman MS, Gilliland DG, Rowe JM (2005) Drug therapy for acute myeloid leukemia. Blood 106: 1154-63

[2] Hayden MS, Ghosh S (2004) Signaling to NF-kappaB. Genes Dev 18: 2195-224

[3] Guzman ML, Neering SJ, Upchurch D, Grimes B, Howard DS, Rizzieri DA, Luger SM, Jordan CT (2001) Nuclear factor-kappaB is constitutively activated in primitive human acute myelogenous leukemia cells. Blood 98: 2301-7

[4] Cilloni D, Martinelli G, Messa F, Baccarani M, Saglio G (2007) Nuclear factor kB as a target for new drug development in myeloid malignancies. Haematologica 92: 1224-9

[5] Nakanishi C, Toi M (2005) Nuclear factor-kappaB inhibitors as sensitizers to anticancer drugs. Nat Rev Cancer 5: 297-309

[6] Schmid JA, Birbach A (2008) IkappaB kinase beta (IKKbeta/IKK2/IKBKB)--a key molecule in signaling to the transcription factor NF-kappaB. Cytokine Growth Factor Rev 19: $157-65$

[7] Karin M, Yamamoto Y, Wang QM (2004) The IKK NF-kappa B system: a treasure trove for drug development. Nat Rev Drug Discov 3: 17-26

[8] Frelin C, Imbert V, Griessinger E, Loubat A, Dreano M, Peyron JF (2003) AS602868, a pharmacological inhibitor of IKK2, reveals the apoptotic potential of TNF-alpha in Jurkat leukemic cells. Oncogene 22: 8187-94

[9] Frelin C, Imbert V, Griessinger E, Peyron AC, Rochet N, Philip P, Dageville C, Sirvent A, Hummelsberger M, Berard E, Dreano M, Sirvent N, Peyron JF (2005) Targeting NF-kappaB activation via pharmacologic inhibition of IKK2-induced apoptosis of human acute myeloid leukemia cells. Blood 105: 804-11

[10] Romagnoli M, Desplanques G, Maiga S, Legouill S, Dreano M, Bataille R, Barille-Nion S (2007) Canonical nuclear factor kappaB pathway inhibition blocks myeloma cell growth and induces apoptosis in strong synergy with TRAIL. Clin Cancer Res 13: 6010-8 
[11] Jourdan M, Moreaux J, Vos JD, Hose D, Mahtouk K, Abouladze M, Robert N, Baudard M, Reme T, Romanelli A, Goldschmidt H, Rossi JF, Dreano M, Klein B (2007) Targeting NFkappaB pathway with an IKK2 inhibitor induces inhibition of multiple myeloma cell growth. $\mathrm{Br} \mathbf{J}$ Haematol 138: 160-8

[12] Lagadec P, Griessinger E, Nawrot MP, Fenouille N, Colosetti P, Imbert V, Mari M, Hofman P, Czerucka D, Rousseau D, Berard E, Dreano M, Peyron JF (2008) Pharmacological targeting of NF-kappaB potentiates the effect of the topoisomerase inhibitor CPT-11 on colon cancer cells. Br J Cancer 98: 335-44

[13] Sors A, Jean-Louis F, Begue E, Parmentier L, Dubertret L, Dreano M, Courtois G, Bachelez H, Michel L (2008) Inhibition of IkappaB kinase subunit 2 in cutaneous T-cell lymphoma down-regulates nuclear factor-kappaB constitutive activation, induces cell death, and potentiates the apoptotic response to antineoplastic chemotherapeutic agents. Clin Cancer Res 14: $901-11$

[14] Griessinger E, Frelin C, Cuburu N, Imbert V, Dageville C, Hummelsberger M, Sirvent N, Dreano M, Peyron JF (2008) Preclinical targeting of NF-kappaB and FLT3 pathways in AML cells. Leukemia 22: 1466-9

[15] Griessinger E, Imbert V, Lagadec P, Gonthier N, Dubreuil P, Romanelli A, Dreano M, Peyron JF (2007) AS602868, a dual inhibitor of IKK2 and FLT3 to target AML cells. Leukemia 21: $877-85$

[16] Shambharkar PB, Blonska M, Pappu BP, Li H, You Y, Sakurai H, Darnay BG, Hara H, Penninger J, Lin X (2007) Phosphorylation and ubiquitination of the IkappaB kinase complex by two distinct signaling pathways. Embo J 26: 1794-805

[17] Jeanpierre S, Nicolini FE, Kaniewski B, Dumontet C, Rimokh R, Puisieux A, MaguerSatta V (2008) BMP4 regulation of human megakaryocytic differentiation is involved in thrombopoietin signaling. Blood 112: 3154-63 
[18] Bolstad BM, Irizarry RA, Astrand M, Speed TP (2003) A comparison of normalization methods for high density oligonucleotide array data based on variance and bias. Bioinformatics 19: $185-93$

[19] Smyth GK (2004) Linear models and empirical bayes methods for assessing differential expression in microarray experiments. Stat Appl Genet Mol Biol 3: Article3

[20] Ashburner M, Ball CA, Blake JA, Botstein D, Butler H, Cherry JM, Davis AP, Dolinski K, Dwight SS, Eppig JT, Harris MA, Hill DP, Issel-Tarver L, Kasarskis A, Lewis S, Matese JC, Richardson JE, Ringwald M, Rubin GM, Sherlock G (2000) Gene ontology: tool for the unification of biology. The Gene Ontology Consortium. Nat Genet 25: 25-9

[21] Guzman ML, Rossi RM, Neelakantan S, Li X, Corbett CA, Hassane DC, Becker MW, Bennett JM, Sullivan E, Lachowicz JL, Vaughan A, Sweeney CJ, Matthews W, Carroll M, Liesveld JL, Crooks PA, Jordan CT (2007) An orally bioavailable parthenolide analog selectively eradicates acute myelogenous leukemia stem and progenitor cells. Blood 110: 4427-35 
Table 1. Effect of AS602868 on hematopoietic precursors. Data are presented as total number of colonies per field and are the mean \pm SD of 3 different experiments (3 different marrow samples). DMSO alone was included as control. MNC: mononuclear derived colony forming cell; CD34: CD34 derived colony forming cells; LTC-IC: longterm culture initiating cells; nd: not determined

\begin{tabular}{ccccccc}
\hline $\begin{array}{c}\text { AS602868 } \\
\mu M\end{array}$ & $\begin{array}{c}\text { MNC } \\
\text { total }\end{array}$ & $\begin{array}{c}\text { MNC } \\
\text { GM }\end{array}$ & $\begin{array}{c}\text { CD34 } \\
\text { total }\end{array}$ & $\begin{array}{c}\text { CD34 } \\
\text { erythroid }\end{array}$ & $\begin{array}{c}\text { CD34 } \\
\text { GM }\end{array}$ & LTC-IC \\
\hline 0 & $9 \pm 1.5$ & $9 \pm 1.7$ & $74 \pm 10$ & $9 \pm 1.3$ & $65 \pm 7.4$ & $4.6 \pm 0.9$ \\
\hline 0.1 & $5.5 \pm 1.7$ & $6.5 \pm 1.6$ & $66 \pm 9.3$ & $8.3 \pm 2.0$ & $57 \pm 6.3$ & $0.9 \pm 0.2$ \\
\hline 0.5 & $23 \pm 3.7$ & $22 \pm 4.3$ & nd & nd & nd & nd \\
\hline 1 & $19 \pm 2.9$ & $20 \pm 3.9$ & $61 \pm 11$ & $7.7 \pm 1.6$ & $53 \pm 4.7$ & $7.1 \pm 1.3$ \\
\hline 5 & $4.5 \pm 0.9$ & $4.5 \pm 1.0$ & $55 \pm 8.4$ & $5.5 \pm 0.9$ & $50 \pm 7.1$ & $0 \pm 0.3$ \\
\hline 10 & nd & nd & $3 \pm 0.8$ & $1 \pm 0.2$ & $3 \pm 1.0$ & - \\
\hline 50 & $0 \pm 0.6$ & $1 \pm 0.6$ & nd & nd & nd & nd \\
\hline
\end{tabular}




\section{FIGURE LEGENDS}

Figure 1. Distribution of sensitivity to AraC and AS602868 for samples in group D. Isolated leukemic blasts were assessed for annexin $\mathrm{V} /$ propidium iodide staining after 18 hours incubation with $10 \mu \mathrm{M}$ AS602868 or $100 \mu \mathrm{M}$ araC. Samples were assigned as insensitive (X) or sensitive ( $\square$ ) according to the increase of annexin V staining after AS602868 exposure.

Figure 2. Sensitivity of fresh AML blasts to AS602868 alone and in combination with AraC (A and D), etoposide ( $B$ and $\mathbf{E}$ ) and daunorubicin (C and F). Isolated leukemic blasts were assessed for annexin V / propidium iodide staining after 18 hours incubation with different concentrations of AS602868 alone or in combination with different concentrations of cytarabine (araC), etoposide (Etop) or daunorubicine (Dauno). Bars indicate the increase in positivity of annexine $\mathrm{V}$ staining as compared to untreated controls.

Figure 3. Mean fluorescence intensity (MFI) of IKBa-staining in lymphocytes (A) and blasts (B) from AML patients. Isolated lymphocytes or leukemic blasts were assessed for I $\mathrm{K} \mathrm{B} \alpha$ expression by flow cytometry after 15 minutes incubation with DMSO (vehicle), $100 \mu \mathrm{M}$ AS602868 (inhibition of IKK2), $1 \mu \mathrm{M}$ PMA $+500 \mathrm{ng} / \mathrm{ml}$ ionomycin (stimulation of IKK2), or a combination of the three latter as described in Material and Methods. 

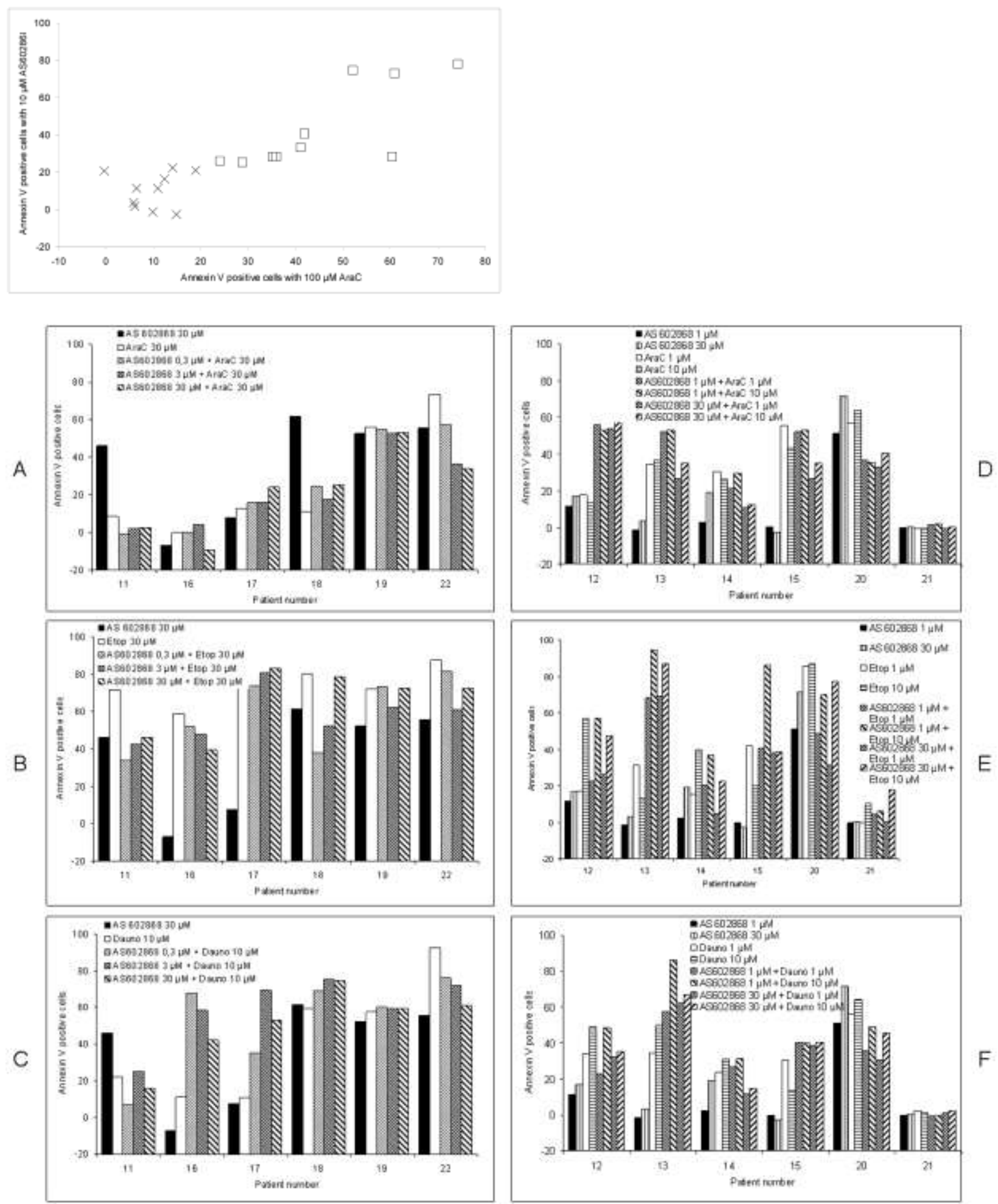

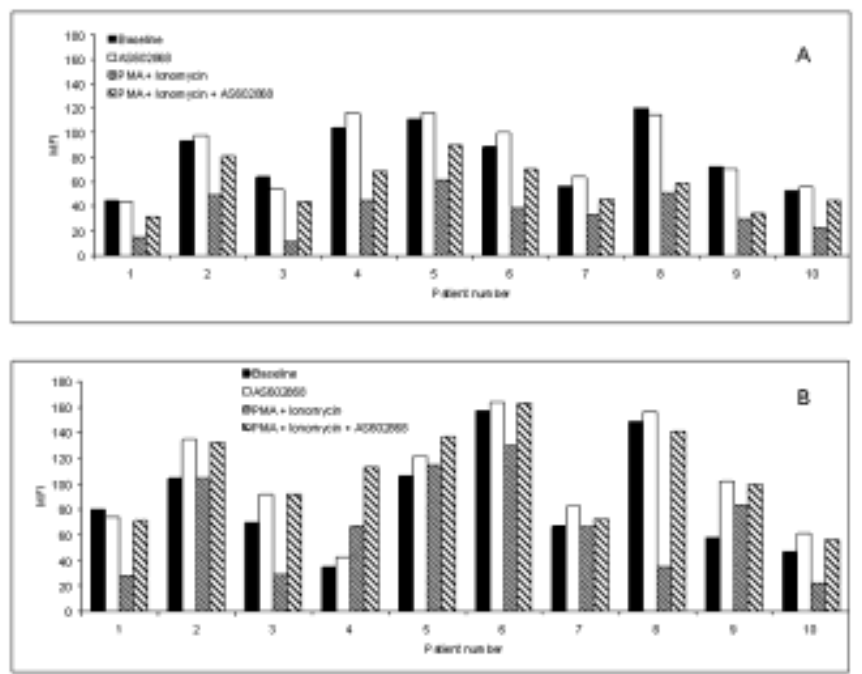